\title{
Phreatic Flow on Sloping Soil Layers from a Finite Source: An Analytical Solution
}

Environmental Assessment and Information Sciences Division Argonne National Laboratory

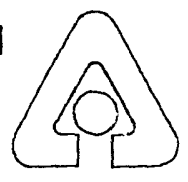

Operated by The University of Chicago, under Contract W-31-109-Eng-38, for the United States Department of Energy 


\section{Argonne National Laboratory}

Argonne National Laboratory, with facilities in the states of Illinois and Idaho, is owned by the United States government, and operated by the University of Chicago under the provisions of a contract with the Department of Energy.

This technical memo is a product of Argonne's Environmental Assessment and Information Sciences (EAIS) Division. For information on the division's scientific and engineering activities, contact:

Director, Environmental Assessment and Information Sciences Division

Argonne National Laboratory

Argonne, Illinois 60439-4815

Telephone (708) 972-3759

Presented in this technical memo are preliminary results of ongoing work or work that is more limited in scope and depth than that described in formal reports issued by the EAIS Division.

\section{Disclaimer}

This report was prepared as an account of work sponsored by an agency of the United States Government. Neither the United States Government nor any agency thereof, nor any of their employees, makes any warranty, express or implied, or assumes any legal liability or responsibility for the accuracy, completeness, or usefulness of any information, apparatus, product, or process disclosed, or represents that its use would not infringe privately owned rights. Reference herein to any specific commercial product, process, or service by trade name, trademark, manufacturer, or otherwise, does not necessarily constitute or imply its endorsement, recommendation, or favoring by the United States Government or any agency thereof. The views and opinions of authors expressed herein do not necessarily state or reflect those of the United States Government or any agency thereof.

Reproduced from the best available copy. Available from the National Technical Information Service (NTIS), U.S. Department of Commerce, 5285 Port Royal Road, Springfield, Virginic 22161.

NTIS price codes:

Printed copy $A 03$

Microfiche 


\section{Phreatic Flow on Sloping Soil Layers from a Finite Source: An Analytical Solution}

by T.H. Filley

Environmental Assessment and Information Sciences Division, Argonne National Laboratory, 9700 South Cass Avenue, Argonne, Illinois 60439 


\section{CONTENTS}

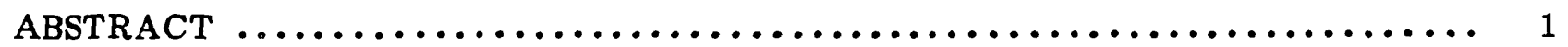

1 INTRODUCTION $\ldots \ldots \ldots \ldots \ldots \ldots \ldots \ldots \ldots \ldots \ldots \ldots \ldots \ldots \ldots \ldots \ldots \ldots \ldots \ldots$

1.1 Mechanism for Infiltrating Water $\ldots \ldots \ldots \ldots \ldots \ldots \ldots \ldots \ldots \ldots \ldots \ldots \ldots$

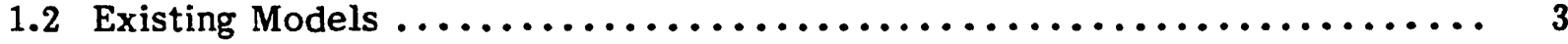

2 MATHEMATICAL DEVELOPMENT $\ldots \ldots \ldots \ldots \ldots \ldots \ldots \ldots \ldots \ldots \ldots \ldots$

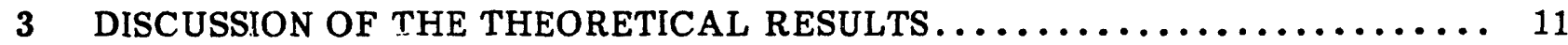

4 VALIDITY OF TIIE APPROXIMATION $\ldots \ldots \ldots \ldots \ldots \ldots \ldots \ldots \ldots \ldots \ldots \ldots \ldots \ldots$

5 APPLICATION OF THE METHOD $\ldots \ldots \ldots \ldots \ldots \ldots \ldots \ldots \ldots \ldots \ldots \ldots \ldots \ldots \ldots$

6 SUMMARY AND CONCLUSIONS $\ldots \ldots \ldots \ldots \ldots \ldots \ldots \ldots \ldots \ldots \ldots \ldots \ldots$

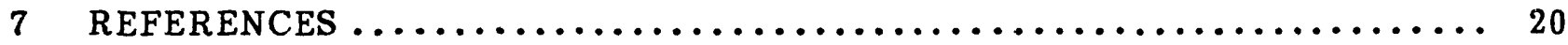

APPENDIX A: Determination of Flow-Window Thickness $\ldots \ldots \ldots \ldots \ldots \ldots \ldots \ldots$

APPENDIX B: Estimation of Time to Steady-State Condition $\ldots \ldots \ldots \ldots \ldots \ldots$

\section{FIGURES}

1 Cross Section of a Phreatic Surface Perched on a Sloping Semipervious Layer $\ldots \ldots \ldots \ldots \ldots \ldots \ldots \ldots \ldots \ldots \ldots \ldots \ldots \ldots \ldots \ldots \ldots \ldots$

2 Leakage through the SPL via the Shortest Path Length $\ldots \ldots \ldots \ldots \ldots \ldots \ldots \ldots$

3 Cross Section of Phreatic Water Ponded beneath a Percolation Sump ......... 10

4 Sensitivity of Saturated Mound Length to Changes in SPL Thickness for a R.ange of SPL Angles ............................... 13

5 Sensitivity of Saturated Mound Length to Changes in SPL Conductivity for a Range of SPL Angles .................................. 13

6 Sensitivity of Saturated Mound I.ength to Changes in Vertical Conductivity for a Range of SPL Angles ....................... 14

7 Sensitivity of Saturated Mound Length to Changes in Evaporation Rate for a Range of SPL Angles . . . . . . . . . . . . . . . . . . . . . . . . 14

8 Sloping SPL Separating a Percolation Sump and the Groundwater Table ....... 15

9 Groundwater Elevation Map of the Southern San Joaquin Valley ........... 16 


\section{FIGURES (Cont'd)}

10 Schematic Structural Cross Section of the Near-Surface Sediments within the Elk Hills and Adjacent San Joaquin Valley ..................

A.1 Cross Section of Flow Segment S on Sloping SPL when the Pressure-Head Gradient is Less than or Equal to the Elevation-Head Gradient ...........

A.2 Cross Section of Flow Segment S on Sloping SPL when the Pressure-Head Gradient is Greater than the Elevation-Head Gradient . . 


\title{
PHREATIC FLOW ON SLOPING SOIL LAYERS FROM A FINITE SOURCE: AN ANAL YTICAL SOLUTION
}

by

\author{
T.H. Filley
}

\begin{abstract}
Sloping clay layers beneath percolation ponds can cause infiltrating wastewater to pond and move in directions not predicted by vertical infiltration equations. This report presents a method for estimating the potential of wastewater from percolation sumps located over sloping clay layers to interact with nearby groundwater resources. The analytical solution developed is for steady-state conditions and includes a procedure to estimate the time needed to reach steady state. The fundamental assumption used in the mathematical development requires that elevation-head gradients be much larger than pressure-head gradients. A method for testing the validity of this assumption is also included. An example calculation was performed for percolation sumps on the Naval Petroleum Reserve No. 1 in Elk Hills, California. That analysis showed that, under the assumptions used, the sumps may have enabled oil field wastewater to reach groundwater resources within the adjacent San Joaquin Valley.
\end{abstract}

\section{INTRODUCTION}

This report examines the potential for waste liquids infiltrating from percolation ponds to migrate along an underlying semipervious layer (SPL) and eventually contaminate groundwater resources. This issue is of concern because (1) seeps in road cuts are evidence of the migration of water along SPLs, and (2) percolation ponds are commonly used as disposal sumps for large volumes of low-quality water. Where these ponds exist over subsurface sloping soils of low permeability, infiltrating contaminants may travel along the top of an SPL and eventually reach and degrade groundwater resources. In this report, an approximate analytical solution is developed to estimate the steady-state behavior of water traveling on a sloping SPL after infiltrating from a constant source percolation pond of finite dimensions. The purpose of this work is to determine the order of magnitude for the migration distance and its dependence on environmental, as well as hydrogeological, conditions. This report presents a steadystate solution to this problem and also estimates the time required for a steady-state groundwater mound to develop. The results will aid in determining the areas or zones of protection required to reduce potential groundwater degradation from both surface and subsurface activities in the unsaturated zone. 


\subsection{MECHANISM FOR INFILTRATING WATER}

Water applied to the ground surface will initially infiltrate unsaturated soil in response to a matric suction gradient. With time, the water content of the sediment increases and matric suction decreases. Infiltration continues under the influence of an elevation (gravity) gradient. The elevation gradient becomes dominant as the sediments become saturated with infiltrating water. As the sediment approaches saturation, the horizontal matric suction gradient is reduced. This is the cause for primarily vertical infiltration through unsaturated sediments. As the infiltration event proceeds, the saturated zone of the moisture profile advances deeper into the soil. Philip (1957) developed an approximate solution for the infiltration of water into an unsaturated soil beneath a shallow surface pond. He represented this process as:

$$
i(t)=s /(2 \sqrt{t})+A
$$

where:

$\mathbf{i}=$ the infiltration rate (length $[\mathrm{L}] /$ time $[\mathrm{T}] \mathrm{l})$,

$s=$ the sorptivity $(\mathrm{L} / \sqrt{\mathrm{T}})$,

$A=a$ constant $(L / T)$, and

$t=$ time from the onset of infiltration $(T)$.

The sorptivity s can be determined from the horizontal infiltration equation

$$
s=I / \sqrt{t}
$$

where:

$I$ = the cumulative infiltration.

In general, sorptivity (s) is a function of the moisture content of the soil. Philip (1969) points out that over time, the first term in Eq. 1 tends towards zero and the infiltration rate $\mathrm{i}$ asymptotically approaches the constant $\mathrm{A}$, which can be approximated by the saturated hydraulic conductivity $\mathrm{K}$ (Eq. 3):

$$
\mathrm{i}=\mathrm{K} \text { as } \mathrm{L} \rightarrow \infty
$$

where:

$\mathrm{K}=$ the saturated hydraulic conductivity. 


\subsection{EXISTING MODELS}

Hantush (1967) developed an analytical solution for constant recharge from a circular area above an existing water-table aquifer perched on a horizontal impermeable clay layer. In that work, the rate of water infiltrating through the unsaturated zone is represented by Eq. 3. Bean and Logan (1983) approximated the travel distance (D) of water ponding on the surface of a sloping clay layer as:

$$
D=V t
$$

and

$$
V=-(K / \Theta)(H / L)
$$

where:

$$
\begin{aligned}
V & =\text { the seepage velocity }(\mathrm{L} / \mathrm{T}), \\
\mathrm{K} & =\text { the saturated hydraulic conductivity }(\mathrm{L} / \mathrm{T}), \\
\Theta & =\text { the sediment porosity, and } \\
H / L & =\text { the slope of the clay layer. }
\end{aligned}
$$

The fundamental approximation used in this treatment is that the drop in elevation head due to a sloping clay layer is much larger than the drop in pressure head of the ponded water. While Bean and Logan (1983) considered water migration along a sloping base, they did not solve for a mass balance, account for a component of pressure head, or simulate leakage through the clay.

\section{MATHEMATICAL DEVELOPMENT}

When ponding occurs on an SPL in the vadose zone, water may evaporate from the phreatic surface as well as leak to the unsaturated or saturated sediments below. To approximate the travel distance of water ponding on a sloping SPL, a solution that incorporates these considerations is developed.

Several assumptions are made to facilitate the solution: (1) the rate of infiltration from the percolation pond is treated as constant; (2) the capillary fringe, known to exist at the phreatic surface, is treated mathematically as an evaporative flux; (3) the soil sediments are treated as homogeneous and anisotropic; and (4) the vertically averaged flow is one-dimensional and parallels the SPL. 
Figure 1 illustrates a cross section of a phreatic surface perched on a sloping SPL. Mathematically, this system may be represented as:

$$
\begin{aligned}
\nabla \cdot \hat{q} & =\frac{\partial}{\partial x} q_{x}+\frac{\partial}{\partial z} q_{z}=0 \\
q_{n} & =-k_{n} \frac{\partial \phi}{\partial n}
\end{aligned}
$$

where:

$$
\begin{aligned}
& \hat{q}=\text { specific discharges, } \\
& \phi=\text { groundwater potential, and } \\
& \mathrm{n}=\text { direction. }
\end{aligned}
$$

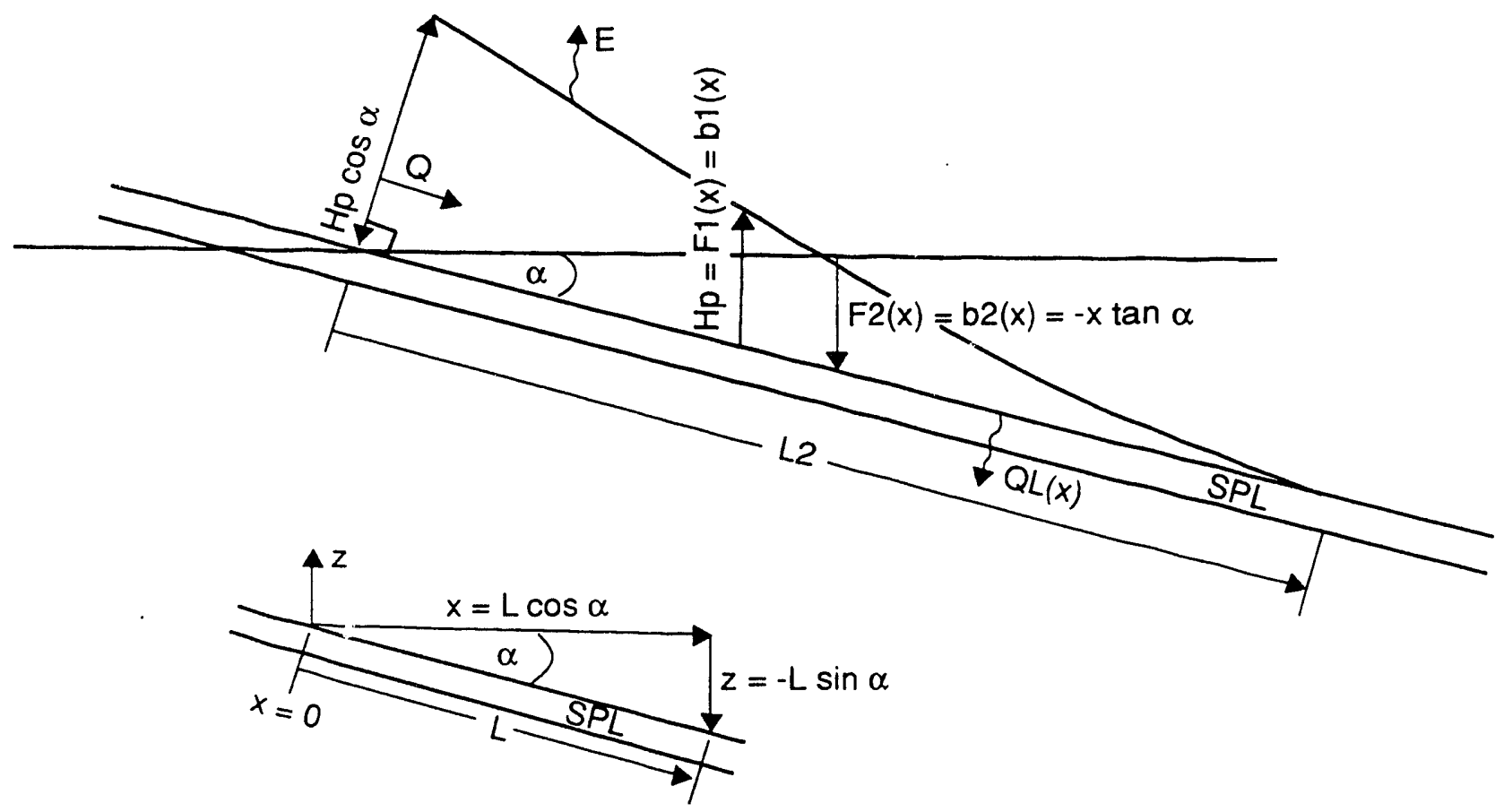

FIGURE 1 Cross Section of a Phreatic Surface Perched on a Sloping Semipervious Layer (SPL) (The illustration also defines terms used within the mathematical development.) 
Equation 6 represents the steady-state continuity equation. Equation 7 represents the evaporative flux $\hat{\mathrm{E}}(\mathrm{L} / \mathrm{T})$ and leakage $\hat{\mathrm{Q}}(\mathrm{L} / \mathrm{T})$ across the phreatic surface and through the SPL, respectively:

$$
\begin{aligned}
\hat{\mathrm{E}} \cdot \nabla F 1 & =-\mathrm{K} \cdot \nabla \phi \mathrm{b} 1 \cdot \nabla F 1 \\
\hat{\mathrm{Q}} \cdot \nabla F 2 & =-\mathrm{K} \cdot \nabla \phi \mathrm{b} 2 \cdot \nabla F 2 \\
\phi & =\frac{\mathrm{P}}{\rho \mathrm{g}}+\mathrm{z}
\end{aligned}
$$

where:

$$
\begin{aligned}
\hat{Q L} & =\text { the leakage across the clay layer, } \\
\nabla & =\text { the gradient operator, } \\
\hat{E} & =\text { the evaporative loss, } \\
P & =\text { the groundwater pressure, } \\
\rho & =\text { the groundwater density, } \\
g & =\text { the acceleration due to gravity, } \\
\mathbf{x}, \mathrm{z} & =\text { the spatial dimensions, } \\
\nabla F 1 & =\text { the gradient of the free water surface, } \\
\nabla F 2 & =\text { the gradient of the sloping base (SPL), } \\
\mathrm{b} 1(\mathrm{x}) & =\text { the height of the free water surface above the SPL, } \\
\mathrm{b} 2(\mathrm{x}) & =\text { the elevation of the SPL, } \\
\phi \mathrm{b} 1 & =\text { the groundwater potential at b1, and } \\
\phi \mathrm{b} 2 & =\text { the groundwater potential at b2. }
\end{aligned}
$$

Integrating Eq. 6 along the vertical between $b 1(x)$ and $b 2(x)$, making use of the Leibnitz rule and after assuming $\phi b 1$ is approximately equal to $\phi b 2$, yields:

$$
-K \frac{d}{d x}[b 1(x)] \frac{d}{d x} H+\hat{q} b 1 \cdot \nabla[z-b 1(x)]-\hat{q} b 2 \cdot \nabla[z-b 2(x)]=0
$$


where:

$\hat{q b} 1=$ the volumetric flux through the surface $\mathrm{F} 1$;

$\hat{q b} 2=$ the volumetric flux through the surface F2; and

$\mathrm{H}=$ the total groundwater head, which replaces $\phi$,

and realizing that the surfaces $F 1$ and $F 2$ can be represented by $(z-b 1)$ and $(z-b 2)$ respectively, yields for $\hat{E}$ and $\hat{Q L}$ :

$$
\begin{aligned}
\hat{E} \cdot \nabla F 1 & =\hat{q} b 1 \cdot \nabla(z-b 1)=-K \cdot \nabla \phi b 1 \cdot \nabla F 1 \\
\hat{Q} L \cdot \nabla F 2 & =\hat{q} b 2 \cdot \nabla(z-b 2)=-K \cdot \nabla \phi b 2 \cdot \nabla F 2
\end{aligned}
$$

Using Eq. 9 in Eq. 8 yields:

$$
-K \frac{d}{d x}[b 1(x)] \frac{d}{d x} I-\hat{Q L} \cdot \nabla F 2+\hat{E} \cdot \nabla F 1=0
$$

which describes phreatic flow with evaporation from the phreatic surface and leakage through a sloping base. The total head $(\mathrm{H})$ in Eq. 10 is defined as:

$$
\mathrm{H}=\mathrm{Hp}+\mathrm{He}
$$

where:

$$
\begin{aligned}
& \mathrm{Hp}=\text { the pressure head equal to } \mathrm{b} 1(\mathrm{x}) \text {, and } \\
& \mathrm{He}=\text { the elevation head equal to } \mathrm{b} 2(\mathrm{x}) \text {. }
\end{aligned}
$$

By using the chain rule and referring to Figure 1 , the rotation of coordinates for constant angle $\alpha$ is accomplished as:

$$
\begin{aligned}
& X=L \cos \alpha \\
& d / d X=(d / d L)(d L / d X)=(d / d L)(1 / \cos \alpha)
\end{aligned}
$$

where:

$\mathrm{L}=$ the distance along the SPL, and

$\mathrm{X}=$ the horizontal distance.

Substitution of Eqs. 11, 12, and 13 into Eq. 10 results in:

$$
-\frac{K}{\cos \alpha} \frac{d}{d L}[b 1(L)] \frac{1}{\cos \alpha} \frac{d}{d L}(H p+H e)-\hat{Q} L \cdot \nabla F 2+\hat{E} \cdot \nabla F 1:=0
$$


Referring to the gradient term $\mathrm{d}[\mathrm{Hp}+\mathrm{He}] / \mathrm{dL}$ in Eq. 14, three situations arise:

$$
\begin{aligned}
& \frac{\mathrm{dHp}}{\mathrm{dL}} \gg \frac{\mathrm{dHe}}{\mathrm{dL}} \\
& \frac{\mathrm{dHp}}{\mathrm{dL}} \cong \frac{\mathrm{dHe}}{\mathrm{dL}} \\
& \frac{\mathrm{dHp}}{\mathrm{dL}} \ll \frac{\mathrm{dHe}}{\mathrm{dL}}
\end{aligned}
$$

When the pressure gradient is much larger than the elevation gradient, the latter can be ignored when solving Eq. 14. When pressure and elevation gradients are of the same magnitude, both must be considered in solving Eq. 14. If the pressure gradient is much less than the elevation gradient, the former can be ignored in the solution of Eq. 14. The solution offered in this report is applicable to the condition in which the pressure-head gradient is much less than the elevation-head gradient. Section 4 presents a means to evaluate the accuracy of this simplifying assumption.

When averaging along the vertical, in sloping phreatic flow systems that are dominated by the slope of the base, the thickness of the flow window perpendicular to the base must be used in the flow equation (Childs 1971). This usage is consistent with the assumption that stream lines are parallel to the sloping base. As shown in Appendix A, two expressions can be derived for the flow window thickness. The application of both depends on the relationship between the pressure-head and elevationhead gradients. For the case in which the pressure-head gradient is less than or equal to the elevation gradient, the window thickness $\{$ Hp $\sin \alpha[\cos \alpha+\tan (\alpha-\beta)]\}$ is used. When the pressure gradient is less than the elevation gradient (when $\alpha \cong \beta$ ), the window thickness can be approximated as [Hp $\cos \alpha$ ]. Substituting [Hp $\cos \alpha$ ] for the window thickness $[\mathrm{b} 1(\mathrm{x})]$, and assuming $\mathrm{dHe} / \mathrm{dL} \gg \mathrm{dHp} / \mathrm{dL}$ in Eq. 14, yields:

$$
-\frac{K}{\cos \alpha} \frac{d}{d L} H p \cos \alpha \frac{d}{\cos \alpha d L}(-L \sin \alpha)=-\hat{E} \cdot \nabla F 1+\hat{Q} L \cdot \nabla F 2
$$

The second term on the right-hand side of Eq. 15, which describes leakage through the sloping SPL, must be expanded. Figure 2 illustrates the leakage term resolved into its components of flow. The derivation assumes that leakage travels through the shortest distance across the SPL (Freeze and Cherry 1979, p. 173). The gradient of $\mathrm{F} 2$ (the equation describing the SPL surface) can be represented as:

$$
\begin{aligned}
\nabla F 2 & =\hat{i}(\partial F 2 / \partial x)+\hat{k}(\partial F 2 / \partial z) \\
& =-[\hat{i}(\sin \alpha / \cos \alpha)+\hat{k}]
\end{aligned}
$$

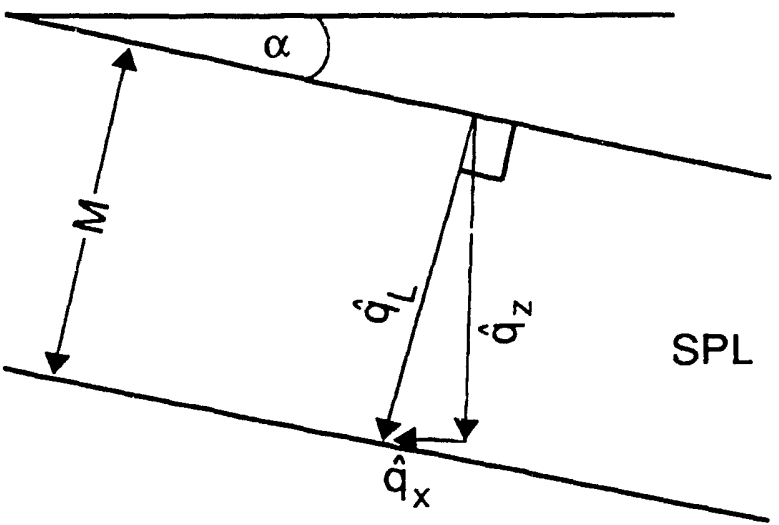

FIGLRE 2 Leakage through the SPL via the Shortest Path Length (The illustration shows the leakage resolved into its components of flow.) 
where:

$\hat{i}$ and $\hat{k}=$ the unit vectors, and

$$
F 2=-L \sin \alpha .
$$

The leakage across the sloping SPL can be resolved into its components as:

$$
\begin{aligned}
& \hat{Q} L=\hat{i}(Q x)+\hat{k}(Q z) \\
& \hat{Q} L=(\hat{i} \sin \alpha+\hat{k} \cos \alpha)\left(K^{\prime} / M\right)(H P+M \cos \alpha)
\end{aligned}
$$

where:

$$
\begin{aligned}
& K^{\prime}=\text { the confining bed conductivity, and } \\
& M=\text { the confining bed thickness. }
\end{aligned}
$$

The leakage across the SPL therefore becomes:

$$
\begin{aligned}
\hat{Q} L \cdot \nabla F 2= & -\left\{\hat{i}(\sin \alpha)\left(K^{\prime} / M\right)[H P+M(\cos \alpha)]\right. \\
& \left.+\hat{k}(\cos \alpha)\left(K^{\prime} / M\right)[H p+M(\cos \alpha)]\right\} \cdot\{\hat{i} \tan \alpha+\hat{k}\} \\
= & -\left\{\left(K^{\prime} / M\right)\left(\left[\left(\sin ^{2} \alpha\right) /(\cos \alpha)\right]+\cos \alpha\right) H_{P}+K^{\prime}\right\}
\end{aligned}
$$

Using the result of Eq. 20 in Eq. 15 yields:

$$
K \frac{d}{d L} H p \frac{d}{d L} L \tan \alpha=-E-\frac{K^{\prime}}{M}\left[\left(\sin ^{2} \alpha / \cos \alpha\right)+\cos \alpha\right] H p-K^{\prime}
$$

which is the equation for phreatic flow along a sloping SPL with leakage and constant evaporation. In Eq. $21, \hat{E} \cdot \nabla F 1$ has been replaced with the scalar $E$ to reflect a spatially constant evaporation rate.

Making the following substitutions in Eg. 21:

$$
\begin{aligned}
& B=\left(K^{\prime} / M\right)\left[\left(\sin ^{2} \alpha\right) /(\cos \alpha)+\cos \alpha\right](1 / \tan \alpha) \\
& A=\left(K^{\prime}+E\right)(1 / \tan \alpha)
\end{aligned}
$$

yields:

$$
-\mathrm{K} \mathrm{dHp} / \mathrm{dL}=\mathrm{BHP}+\mathrm{A}
$$


This equation can be integrated to yield:

$$
\frac{K}{B} \ln (A+B H p)=-L+C
$$

where $\mathrm{C}$ is an arbitrary constant.

Equation 25 can be rearranged to solve for the mounded pressure head Hp:

$$
\operatorname{Lip}=\frac{1}{B}\{[\exp B(C-L) / K]-A\}
$$

The constant $\mathrm{C}$ is evaluated by recognizing that, at the water mound's leading edge on the SPL $(\mathrm{L}=\mathrm{L} 2)$, the flux parallel to the SPL must be equal to zero. This can be stated as:

$$
\left.Q\right|_{L 2}=K \frac{1}{B}\{[\exp B(C-L 2) / K]-A\}(\cos \alpha)(\sin \alpha)=0
$$

Solving for $\mathrm{C}$ and substituting into Eq. 26 yields:

$$
H p=\frac{A}{B}\{(\exp [(B / K)(L 2-L)]-1)\}
$$

The length of the mound can now be determined by recognizing that, at a point where $\mathrm{L}$ equals 0 , Hp equals Ho (pressure head at the origin).

$$
L 2=\frac{K}{B} \ln [(B / A) H o+1]
$$

Equation 29 determines the steady-state migration distance of phreatic water traveling on a perched sloping leaky layf $r$ with evaporation and a thickness of flow Ho at the origin.

To determine the value of the head at the origin, an approximate volume integral analysis is performed for the volume of water ponded beneath the percolation sump. As illustrated in Figure 3, this is accomplished by recognizing that the quantity of water that flows downslope must be equal to the algebraic sum of water that leaks through the SPL beneath the pond, evaporates from the phreatic surface, and infiltrates from the pond. This may be stated as:

$$
Q=Q L+Q E+Q I
$$

where:

$$
\begin{aligned}
& Q=\text { the rate moving down slope, } \mathrm{L}^{2} / \mathrm{T} ; \\
& \mathrm{QI}=\text { the rate infiltrating from beneath the percolation pond, } \mathrm{L}^{2} / \mathrm{T} ; \\
& \mathrm{QL}=\text { the rate leaking through the sloping SPL beneath the pond, } \mathrm{L}^{2} / \mathrm{T} ; \\
& \text { and } \\
& \mathrm{QE}=\text { the evaporation rate, } \mathrm{L}^{2} / \mathrm{T} \text {. }
\end{aligned}
$$




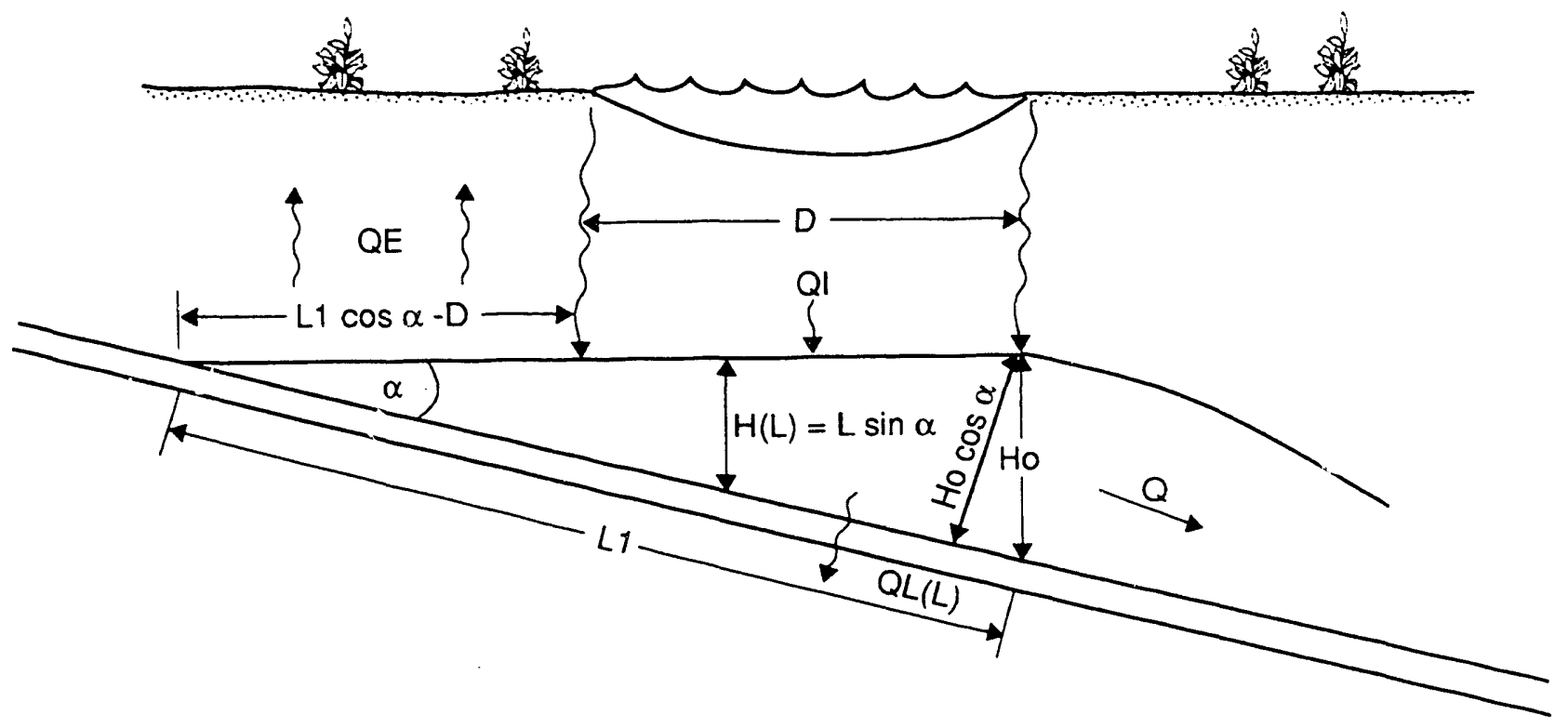

FIGURE 3 Cross Section of Phreatic Water Ponded bersath a Percolation Sump (The illustration defines terms used within the integral volume analysis for determination of the ponded head at $X=0$, Ho.)

The infiltration rate is calculated as the product of the vertical saturated hydraulic conductivity $\mathrm{K} 2$ and the percolation pond dimension $\mathrm{D}$ :

$$
Q I=K 2 \quad D
$$

The rate of leakage across the SPL beneath the pond is approximated by replacing Hp in Eq. 20 with $\mathrm{L} \sin \propto$ (see Figure 3 ) and then integrating along the length of the SPL. This is considered an approximation because it implies a flat phreatic surface beneath the pond.

$$
\mathrm{QL}=\frac{\mathrm{GHO}^{2}}{2 \sin \alpha}+\mathrm{K}^{\prime} \mathrm{Ho} / \mathrm{sin} \alpha
$$

where:

$$
\begin{aligned}
& G=\left(K^{\prime} / M\right)\left[\left(\sin ^{2} \alpha\right) /(\cos \alpha)+\cos \alpha\right], \text { and } \\
& H o=L 1 \sin \alpha .
\end{aligned}
$$

The evaporation rate from the free phreatic surface can be approximated by subtracting the sump dimension $D$ from the horizontal component of L1 (L1 $\cos \alpha$ [see Figure 3]) and then multiplying by $\mathrm{E}$ :

$$
\begin{aligned}
Q E & =E(L 1 \cos \alpha-D) \\
& =E[H o(\cos \alpha / \sin \alpha)-D]
\end{aligned}
$$


The rate moving downslope can be calculated by using the window thickness (Ho $\cos \alpha$ ) and the elevation gradient $(\sin \alpha)$ to determine $Q$ as:

$$
Q=K H o \cos \alpha \sin \alpha
$$

Using Eqs. 31-34 in Eq. 30 yields:

$$
\mathrm{Al} \mathrm{Ho}^{2}+\mathrm{Bl} \mathrm{Ho}+\mathrm{Cl}=0
$$

where:

$$
\begin{aligned}
\mathrm{A} 1 & =[\gamma /(\alpha 1 \mathrm{D})](\tan \alpha+1 / \tan \alpha) / 2, \\
\mathrm{~B} 1 & =[1 /(\alpha 1 \sin \alpha)]+\cos \alpha \sin \alpha+[\cos \alpha /(\delta \sin \alpha)], \\
\mathrm{C} 1 & =-\mathrm{D}[(1 / \beta)+(1 / \delta)], \\
\mathrm{K}^{\prime} & =\mathrm{K} / \alpha 1, \\
\mathrm{~K} 2 & =\mathrm{K} / \mathrm{B}, \\
\mathrm{M} & =\mathrm{D} / \gamma, \\
\mathrm{E} & =\mathrm{K} / \delta, \text { and }
\end{aligned}
$$

$\alpha 1, \beta, \gamma$, and $\delta=$ dimensionless parameters.

The solution to Eq. 35 is:

$$
\mathrm{Ho}=\left[-\mathrm{B} 1+\left(\mathrm{BI}^{2}+4 \mathrm{Al} C \mathrm{Cl}\right)^{1 / 2}\right] / 2 \mathrm{Al}
$$

Equation 3? represents the positive root of Eq. 35 only because a negative value for Ho has no physical meaning in this analysis. The resu.'t from Eq. 36 can be used directly in Eq. 29 to determine the length of mounding.

\section{DISCUSSION OF THE THEORETICAL RESUI,TS}

The saturated mound length (Eq. 29) was investigated for its sensitivity to hydrologic and environmental parameters. These parameters include SPL thickness $\mathrm{M}$, SPL conductivity $\mathrm{K}$ ', porous medium vertical conductivity $\mathrm{K} 2$, and evaporation rate $\mathrm{E}$. These parameters are rendered dimensionless in Eqs. 29 and 35 through the definitions $\mathrm{M}=\mathrm{D} / \gamma, \mathrm{K}^{\prime}=\mathrm{K} / \alpha 1, \mathrm{~K} 2=\mathrm{K} / \mathrm{B}$, and $\mathrm{E}=\mathrm{K} / \delta$. In these relationships, $\alpha 1, \quad B$, $\gamma$, and $\delta$ are dimensionless scaling factors, and $D(f t)$ and $K(f t / d)$ are the sump dimension and porous-medium saturated hydraulic conductivity, respectively. As the magnitude of the scaling factors is increased, the hydrologic and environmental parameters decrease. 
Figure 4 plots the predicted mound length as a function of the SPL angle for the family of curves $M=D / \gamma$. The plot investigates a range of SPL thicknesses between $\mathrm{D} / 10$ and $\mathrm{D} / 10^{3}$. In general, the saturated mound length $\mathrm{L} 2 / \mathrm{D}$ increases as $M$ increases. The parameter $L 2 / D$ is very sensitive to the value of $M$ at low values of $M$, but, as $M$ approaches $D$, the sensitivity of $L 2 / D$ to the value of $M$ decreases. For smaller values of $M, L 2 / D$ shows a higher sensitivity to the SPL angle for small angles.

Figure 5 plots L2/D as a function of the SPL angle for the family of curves $\mathrm{K}^{\prime}=\mathrm{K} / \alpha 1$. The plot investigates a range of $\mathrm{SPL}$ conductivities from $\mathrm{K} / 10^{3}$ to $\mathrm{K} / 10^{5}$. The parameter L2/D increases with decreasing SPL conductivity. Figure 6 plots L2/D as a function of the SPL angle for the family of curves $\mathrm{K} 2=\mathrm{K} / \mathrm{B}$. The plot investigates a range of porous medium vertical conductivities between $K$ and $K / 10^{3}$. The value of $L 2 / D$ increases with increasing vertical conductivity. Figure 7 plots L2/D as a function of the SPL angle for the family of curves $E=K / \delta$. The plot investigates a range of evaporation rates between $\mathrm{K} / 10$ and $\mathrm{K} / 10^{3}$. The value of $L 2 / D$ increases with decreasing evaporation rate.

Comparison of the plots shows that the mound length L2/D is most sensitive to the evaporation rate $E$. An order of magnitude change in the dimensionless parameter $\delta$ produces an order of magnitude change in L2/D. Figures 4, 5, and 6, which plot the sensitivity of L2/D to SPL thickness, SPL conductivity, and porous media vertical conductivity, respectively, show a limiting behavior. Figure 4 illustrates that as $\gamma$ decreases (increasing $M$ ), the confining bed becomes thicker, and the quantity of leakage across the SPL is controlled by the $K^{\prime}$ term of Eq. 21, which is independent of $M$. Figure 5 shows that as $\alpha 1$ increases (decreasing $K^{\prime}$ ), the quantity of leakage across the SPL is attenuated, and the $K$ ' dependent sink terms of Eq. 29 are minimized with respect to the evaporation rate $\mathrm{E}$. Similar behavior is observed in Figure 6, where, in the limit of low vertical conductivity K2, Egs. 29 and 35 become less sensitive to that parameter and are controlled by the evaporation rate and SPL thickness.

\section{VALIDITY OF THE APPROXIMATION}

The validity of assuming that the elevation gradient is dominant can be investigated. Equation 28 calculates the predicted value of the pressure head Hp. Taking the derivative with respect to $L$ results in:

$$
\frac{d h p}{d L}=-\frac{A}{K}\left[\exp \frac{B}{K}(L 2-L)\right]
$$

This equation shows that the maximum negative pressure-head gradient occurs at $\mathrm{L}=0$, and therefore that:

$$
\left.\frac{d h p}{d L}\right|_{\max }=-\frac{A}{K}\left[\exp \frac{B}{K} L 2\right]
$$




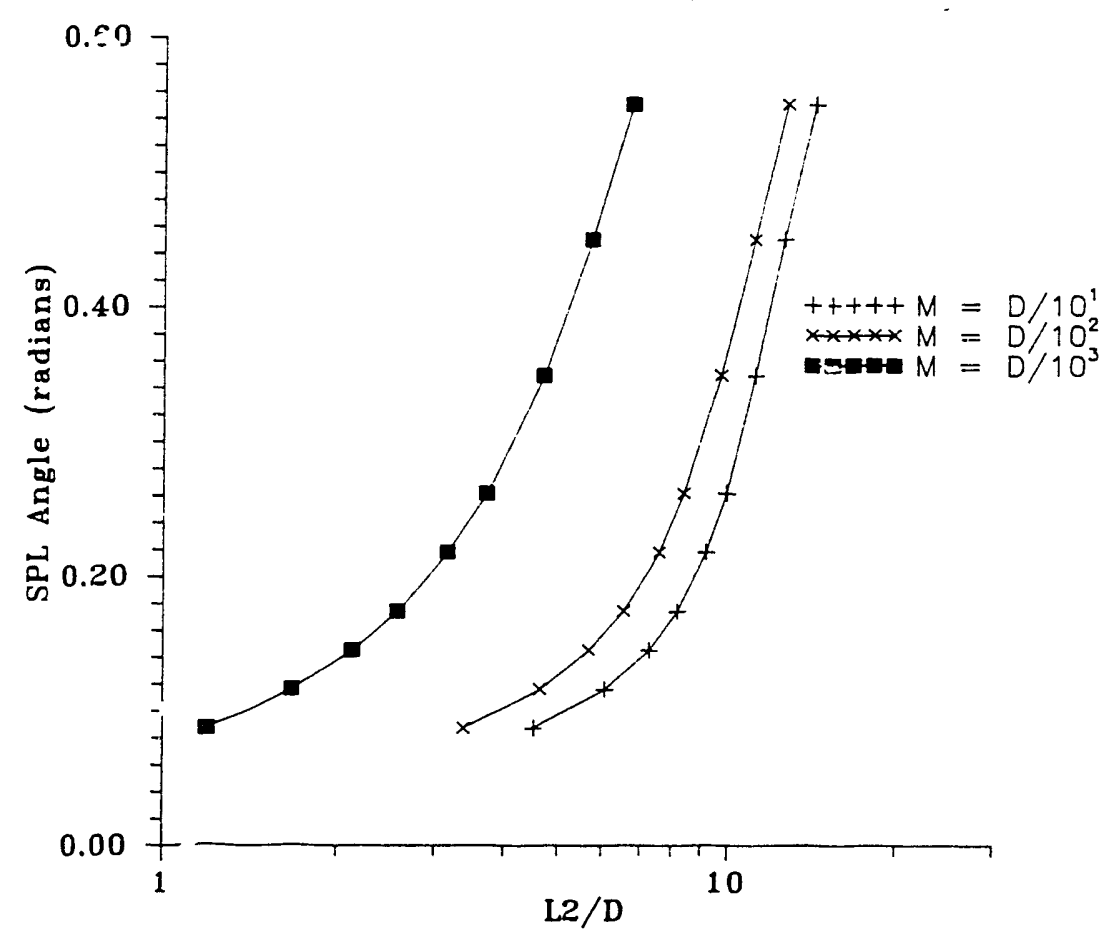

FIGURE \& Sensitivity of Saturated Mound Length (L2/D) to Changes in SPL Thickness (M) for a Range of SPL Angles

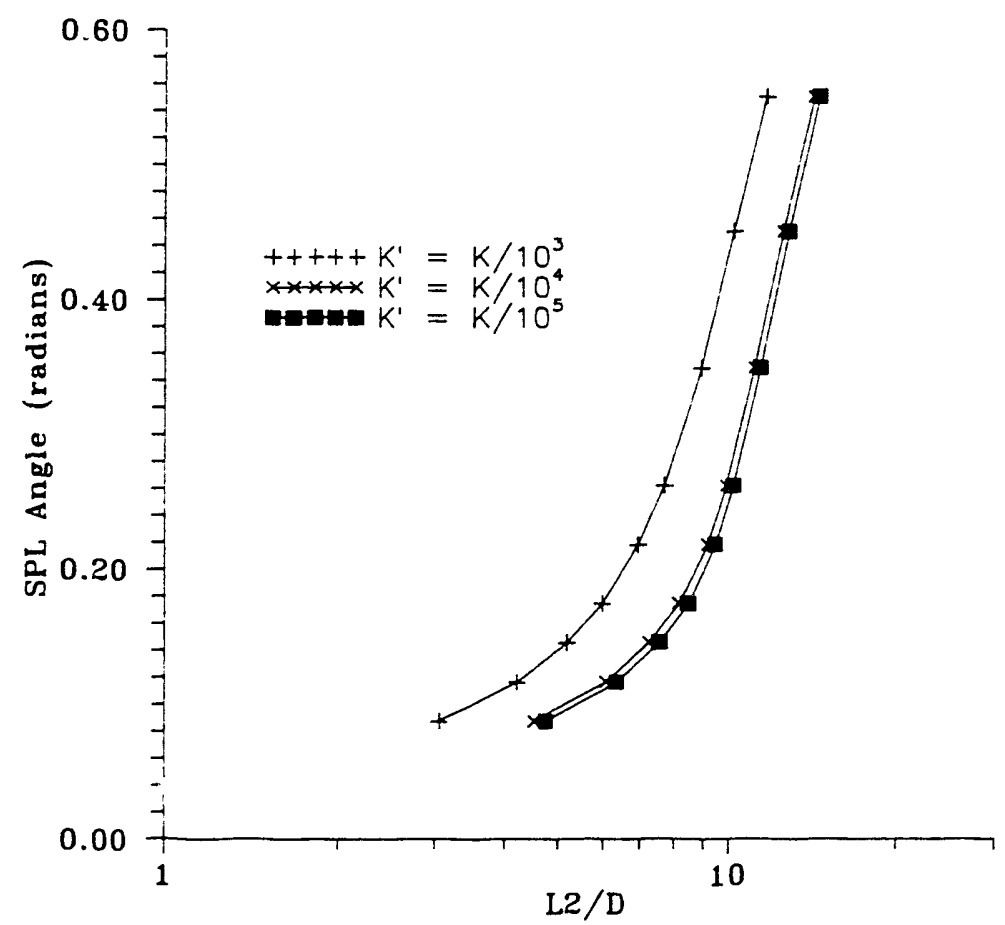

FIGURE 5 Sensitivity of Saturated Mound Length (L2/D) to Changes in SPL Conductivity (K') for a Range of SPL Angles 


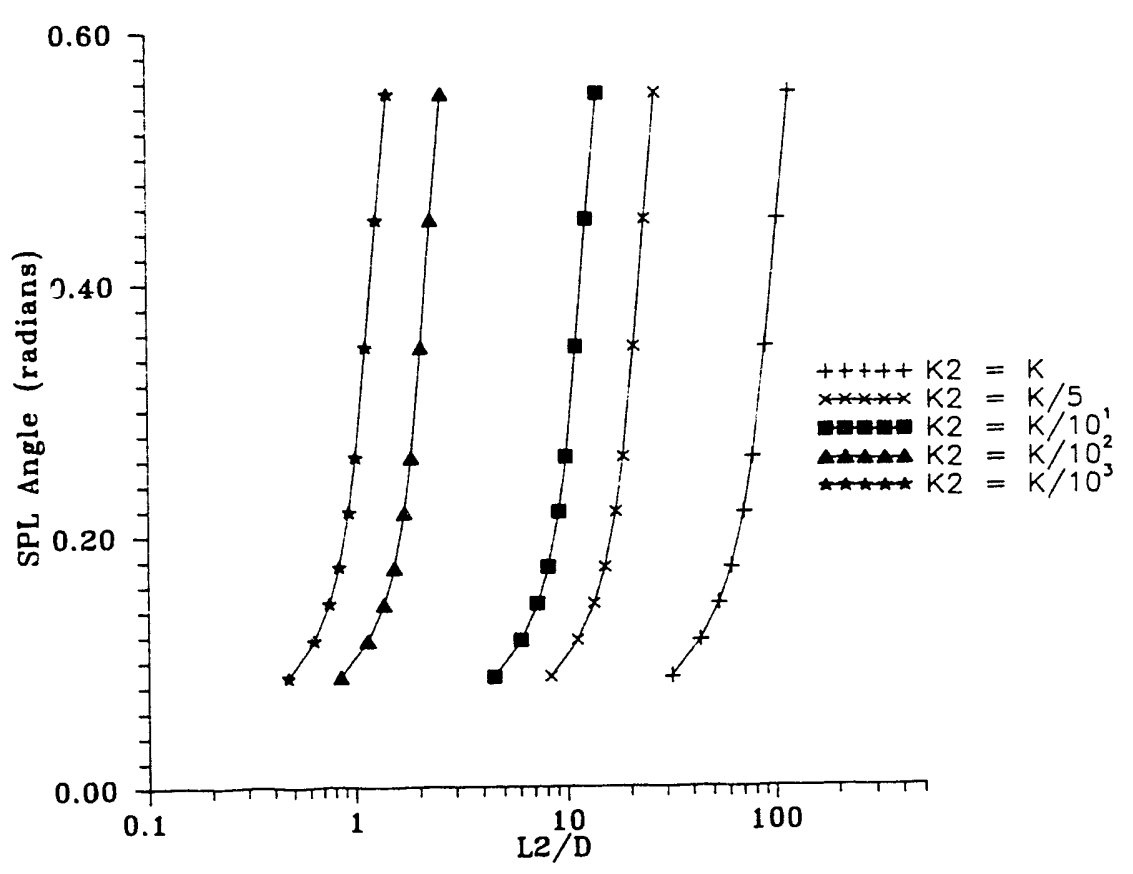

FIGURE 6 Sensitivity of Saturated Mound Length (L2/D) to Changes in Vertical Conductivity (K2) for a Range of SPL Angles

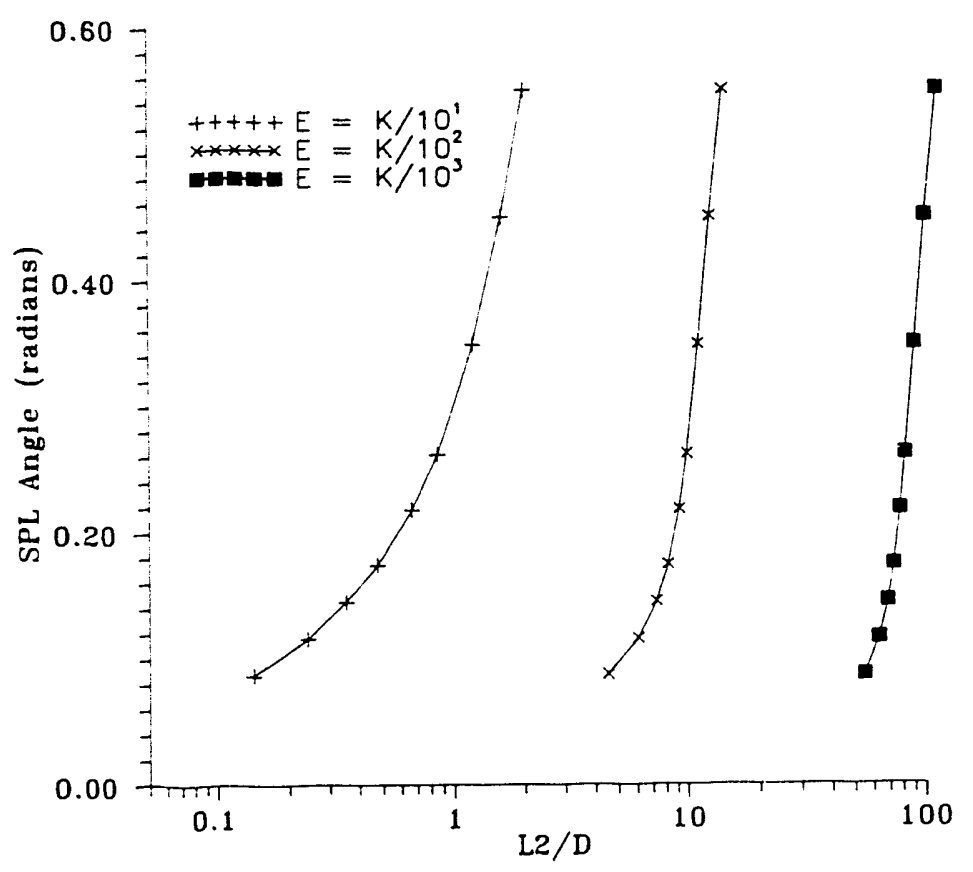

FIGURE 7 Sensitivity of Saturated Mound Length (L2/D) to Changes in Evaporation Rate (E) for a Range of SPL Angles 
After substituting in for the value of $\mathrm{L2}, \mathrm{A}$, and $\mathrm{B}$, rearrangement yields:

$$
\left.\frac{\mathrm{dhp}}{\mathrm{dL}}\right|_{\max }=-\left[\frac{D}{M \alpha 1 \cos \alpha}+\left(\frac{1}{\alpha 1}+\frac{1}{\delta}\right) \frac{\cos \alpha}{\sin \alpha}\right]
$$

The constraining assumption was $\mathrm{dHp} / \mathrm{dL} \ll \mathrm{dHe} / \mathrm{dL}=\sin \alpha$ and using this, Eq. 39 yields:

$$
\sin \alpha \gg \frac{D}{M \alpha 1 \cos \alpha}+\left(\frac{1}{\alpha 1}+\frac{1}{\delta}\right) \frac{\cos \alpha}{\sin \alpha}
$$

Equation 40 can be used to test the validity of assuming $\mathrm{dHp} / \mathrm{dL} \ll \mathrm{dHe} / \mathrm{dL}$ in the mound-length calculations.

\section{APPLICATION OF THE METHOD}

Figure 8 illustrates a sloping, semipervious clay layer (SPL) separating a percolation sump from the groundwater table. The calculation L2/D (Eq. 29) predicts the length of mounded water on the SPL. The calculation is intended to estimate if the mound will reach the water table and therefore possibly contaminate the groundwater. This condition, as illustrated in the figure, occurs when L2 $\sin \alpha \geq H$. As an example of

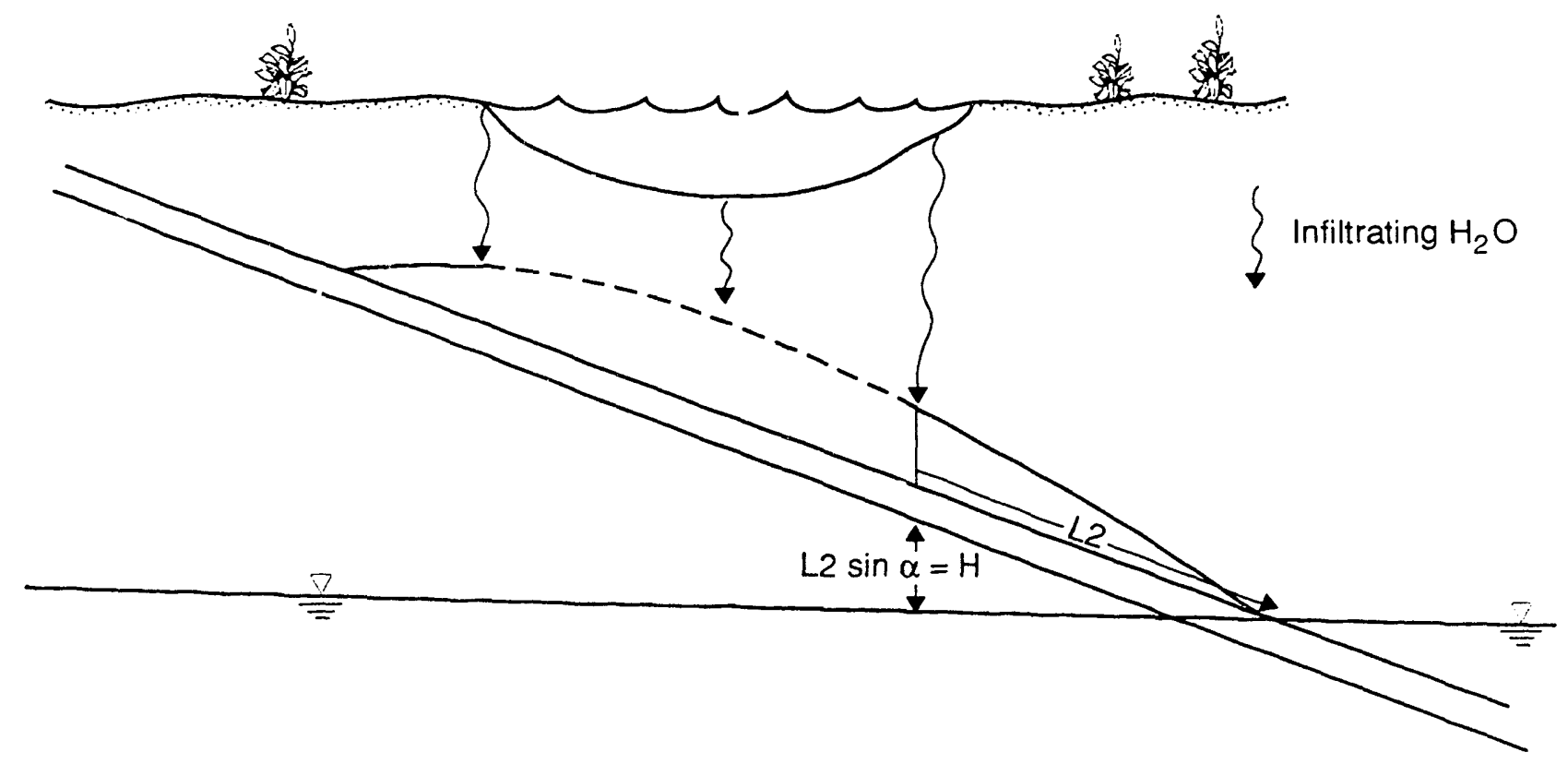

FIGURE 8 Sloping SPL Separating a Percolation Sump and the Groundwater Table (The illustration defines terms used within the example calculation. The water table is intersected by mounded percolation water when L2 $\sin \alpha>\mathrm{H}_{\text {.) }}$ 
the method, a case study is performed for wastewater sumps located on the Naval Petroieum Reserve No. 1 (NPR-1) in Elk Hills, California.

Bean and Logan (1983) hypothesized that percolation sumps on the periphery of NPR-1 were the cause of groundwater degradation observed in nearby wells in the shallow aquifer of the adjacent San Joaquin Valley. Figure 9, a groundwater elevation map, shows the location of the Elk Hills (which contains NPR-1) and the approximate locations of percolation sumps and groundwater production wells of the San Joaquin Valley. Also shown is the location of the Kern Water Bank, a state-operated groundwater storage area.

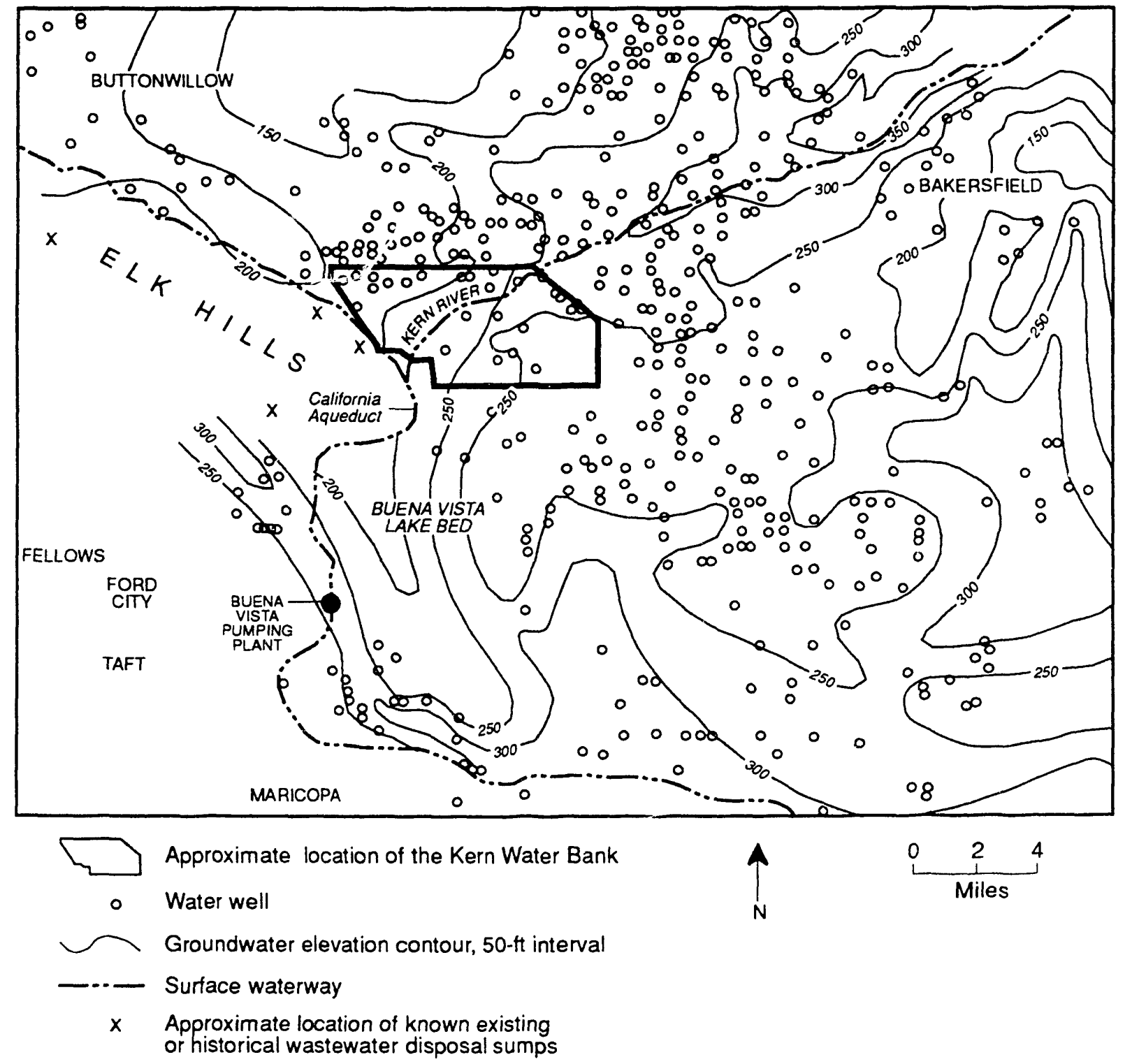

FIGURE 9 Groundwater Elevation Map of the Southern San Joaquin Valley (The illustration shows the location of the Elk Hills and its proximity to groundwater wells and to the Kern Water Bank, a state-operated groundwater storage program.) 
The NPR-1 cove:'s approximately 46,000 acres within the Elk Hills near Bakersfield, California. The Elk Hills are formed by a large northwest- to southeasttrending anticlinal structure. Along the crest of anticline, the surface sediment structure dips from 3 to 4 degrees, while along the periphery the dip is somewhat greater. The surface sediments constitute the Tulare Formation, which consists of a mixture of coarse to fine sands and conglomerates interbedded with silts and mudstones (Maher, Carter, and Lantz 1975). The thickness of the mudstone varies from a few feet to several tens of feet. The Tulare ranges from $622 \mathrm{ft}$ thick along the crests of the anticline to more than $2,000 \mathrm{ft}$ thick along the southern flank of the anticline. Within the adjacent San Joaquin Valley, the Tulare Formation constitutes a "confined" aquifer of high-quality groundwater. This aquifer is a principal source of domestic, commercial, and agricultural water in the area. Figure 10 is a conceptualization of the structure of the Tulare Formation within the Elk Hills. This figure shows the relationship of these sediments to aquifers within the San Joaquin Valley, and how percolation sumps may interact with groundwater as described in this report.

The San Joaquin Valley is arid. During 1986, approximately 70 in. of water $(0.0159 \mathrm{ft} / \mathrm{d})$ were observed to evaporate at a monitoring station in Bakersfield (Kern County Water Agency [KCWA] 1987). The northern and northeastern periphery of the Elk Hills is located within the margin of the San Joaquin Valley where the depth to groundwater is 20 to $120 \mathrm{ft}$ (KCWA 1987). In the 1970s, the California Department of

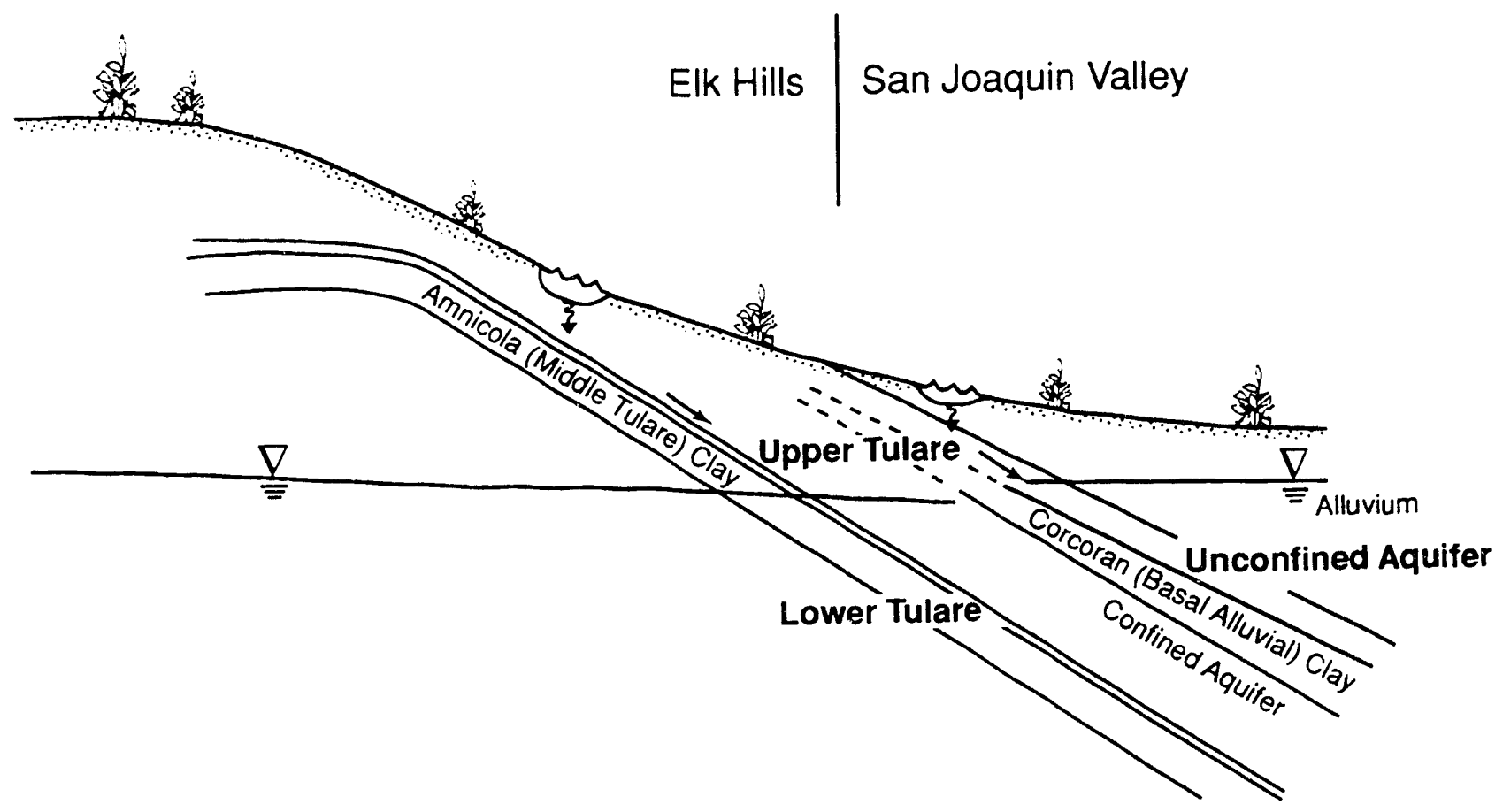

FIGURE 10 Schematic Structural Cross Section of the Near-Surface Sediments within the Elk Hills and Adjacent San Joaquin Valley (The illustration shows the relationship between surface sediments on the Elk Hills and aquifers [groundwater resources] of the adjacent San Joaquin Valley.) 
Water Resources and Kern County Water Agency collaborated to numerically simulate the flow field of the southern San Joaquin Valley (CDWR/KCWA 1977). Their model calibration indicated that the horizontal hydraulic conductivity of the Tulare sediments within the confined aquifer was $30 \mathrm{ft} / \mathrm{d}$. The vertical conductivity of the Tulare sediments can be estimated to be an order of magnitude less than the horizontal component (Freeze and Cherry 1979). This condition (i.e., a 10:1 horizontal to vertical conductivity ratio) is treated here as case 1.

Although this relationship between the horizontal and vertical conductivity components may be valid for undisturbed groundwater flow systems, infiltrating water in the unsaturated zone can redistribute the fine sediment fraction and thus reduce the vertical conductivity. To extend the useful life of percolation ponds, oil field operators are required to periodically dynamite the sump bottom sediments. In this report, finesediment redistribution has been estimated to reduce vertical conductivity to two orders of magnitude less than horizontal conductivity (i.e., to a 100:1 horizontal to vertical ratio). This is considered an extreme condition and is treated in this analysis as case 2. No data on the hydraulic conductivity of the clay zones are known to be available; however, based on methodology in Freeze and Cherry (1979), a conductivity range of $10^{-3}$ to $10^{-5} \mathrm{ft} / \mathrm{d}$ can be estimated. A sump dimension (length or width) of 50 to $100 \mathrm{ft}$ can be estimated for NPR-1.

Conservative estimates of $10^{-3} \mathrm{ft} / \mathrm{d}, 5 \mathrm{ft}$, and $50 \mathrm{ft}$ were selected for the SPL conductivity, SPL thickness, and sump dimension, respectively. If these values are used, the dimensionless parameters $\alpha 1, \beta, \gamma$, and $\delta$ are calculated for case 1 as:

$$
\begin{aligned}
& \alpha 1=K / K^{\prime}=(30 \mathrm{ft} / \mathrm{d}) /\left(10^{-3} \mathrm{ft} / \mathrm{d}\right)=3 \times 10^{4} \\
& B=K / K 2=(30 \mathrm{ft} / \mathrm{d}) /(3 \mathrm{ft} / \mathrm{d})=10 \\
& \gamma=D / M=50 \mathrm{ft} / 5 \mathrm{ft}=10 \\
& \delta=K / E=(30 \mathrm{ft} / \mathrm{d}) /(0.0159 \mathrm{ft} / \mathrm{d})=1,877
\end{aligned}
$$

The dimensionless parameters $\alpha 1, \beta, \gamma$, and $\delta$ are calculated for case 2 in the same manner as for case 1 . Using the case 1 parameter values and a 6-degree dip on the Tulare structure near the Elk Hills periphery in Eq. 36 yields a prediction of $46 \mathrm{ft}$ for the flow window thickness Ho. The length of the mound L2 is calculated from Eq. 29 as $6,500 \mathrm{ft}$. For case 2, Eqs. 36 and 29 yield estimates for Ho and L2 of 4.8 and $850 \mathrm{ft}$, respectively. The criteria for interaction with the groundwater body (L2 $\sin \alpha \geq \mathrm{H}$ ) (see Figure 8) can be used to calculate:

\section{Case 1}

$\mathrm{L} 2 \sin \alpha=6,500 \mathrm{ft} \times 0.10453=679 \mathrm{ft}$

Case 2

$\mathrm{L} 2 \sin \alpha=850 \mathrm{ft} \times 0.10453=89 \mathrm{ft}$ 
Because the groundwater body $(\mathrm{H})$ is 20 to $120 \mathrm{ft}$ below the ground surface, both cases 1 and 2 may produce mounds of sufficient length to reach the saturated groundwater zone. This exercise shows that the hypothesis of Bean and Logan (1983), which states that percolation ponds on the northeastern flank of NPR-1 interacted with groundwater resources of the San Joaquin Valley, may be correct. To check the validity of the solution obtained in this section, Eq. 40 is used to yield: $\sin \alpha=$ 0.10453 > 0.00571 , and the criterion is met.

As developed in Appendix B, estimates of upper and lower limits can be calculated for the time required to form the steady-state mound lengths calculated in cases 1 and 2. Using Eqs. B.3, B.4, and B.5 and assuming an effective sediment porosity of 0.5 and a distance of $50 \mathrm{ft}$ between the sump bottom and the SPL, these bounding limits are calculated to be:

$\begin{array}{lcc}\text { Case } & \begin{array}{c}\text { Lower Limit } \\ \text { (years) }\end{array} & \begin{array}{c}\text { Upper Limit } \\ \text { (yea-s) }\end{array} \\ \text { Case 1 } & 1.3 & 2.6 \\ \text { Case 2 } & 0.4 & 0.8\end{array}$

This calculation indicates that even under conservative conditions, a steady-state interaction between the groundwater body and waste liquids percolating from the sumps could be established within 3 years after continuous use of the sumps began.

\section{SUMMARY AND CONCLUSIONS}

The analytical technique developed in this report provides a means of evaluating steady-state phreatic elevation-gradient flow on a sloping semipervious layer (SPL). The methodology takes into account pressure-gradient-driven leakage across a sloping SPL, evaporation from the phreatic surface, homogeneous and anisotropic aquifer hydraulic conductivity, and a finite source of infiltration water. Sensitivity analysis indicates that travel distance for the perched flow is very sensitive to (1) the degree of aquifer anisotropy and (2) the evaporation rate from the phreatic surface. This report also provides methods for analyzing the accuracy of the elevation-gradient approximation and for estimating the time required to reach a steady-state condition.

The application of this methodology is focused on evaluating potential impacts to groundwater resources from infiltrating wastewaters above the SPL. This study indicates that presence of a saturated, sloping SPL can cause water infiltrating from constantsource percolation ponds to move large distances along the SPL. In the demonstration case presented -- infiltration of wastewater from percolation ponds on the Naval Petroleum Reserve No. 1 in California -- the calculations indicate that, under the assumptions used, a steady-state interaction could develop between the infiltrating wastewater and the underlying groundwater. 
It can be concluded from these results that, when sloping clay layers form part of the underlying geologic structure, this travel mechanism to the water table must be taken into consideration in evaluating potential impacts to groundwater from contaminated fluids ciisposed of in percolation ponds.

\section{REFERENCES}

Bean, R.T., and J. Logan, 1983, Lower Westside Water Quality Investigation - Kern County, prepared for California State Water Resources Control Board, Contract No. 2-096-158-0, Bakersfield, Calif.

California Department of Water Resources and Kern County Water Agency, 1977, Kern County Groundwater Model, Fresno, Calif.

Childs, E.C., 1971, Drainage of Groundwater Resting on a Sloping Bed, Water Resources Research, 7(55):1256-1263.

Freeze, R.A., and J.C. Cherry, 1979, Groundwater, Prentice Hall, Englewood Cliffs $s_{₹}$ N.J.

Hantush, M.S., 1967, Growth and Decay of Groundwater Mounds in Response to Uniform Percolation, Water Resources Research, 3:227-234.

Kern County Water Agency, 1987, Water Supply Report, 1986, Bakersfield, Calif.

Maher, J.C., R.D. Carter, and R.J. Lantz, 1975, Petroleum Geology of Naval Petroleum Reserve No. 1, Elk Hills, Kern County, California, U.S. Geological Survey Professional Paper 912, Washington, D.C.

Philip, J.R., 1957, The Theory of Infiltration: 4. Sorptivity and Algebraic Infiltration Equations, Soil Science, 84:257-264.

Philip, J.R., 1969, Theory of Infiltration, Advances in Hydroscience, 5:215-296. 
APPENDIX A:

DETERMINATION OF FLOW-WINDOW THICKNESS 


\section{APPENDIX A: \\ DETERMINATION OF FLOW-WINDOW THICKNESS}

In swiping phreatic flow systems that are dominated by the slope of the base, the thickness of the flow window perpendiculac to the base must be used in the flow equation (Childs 1971). This usage is consistent with the assumption that stream lines are parallel to the slcining base. Two expressions can be derived for the flow-window thickness. Their application depends on the relationship between the pressure-head and elevationhead gradients.

Figure A.1 treats the case where the pressure-head gradient is approximately equal to or less than the elevation gradient. Figure A.2 illustrates the case where the elevation gradient is less than the pressure gradient. The two figures show the water surface segment $S$, in the limit of the distance $d L$ (see Figures A.1 and A.2), becoming very small. having an angle $B$ from the horizontal. The angle of the semipervious layer (SPL) from the horizontal is given as $\alpha$. The term Hp represents the pressure head on the SPL, and $T$ is the window thickness measured from the SPL to the water surface at some sniall distance dL down slope.

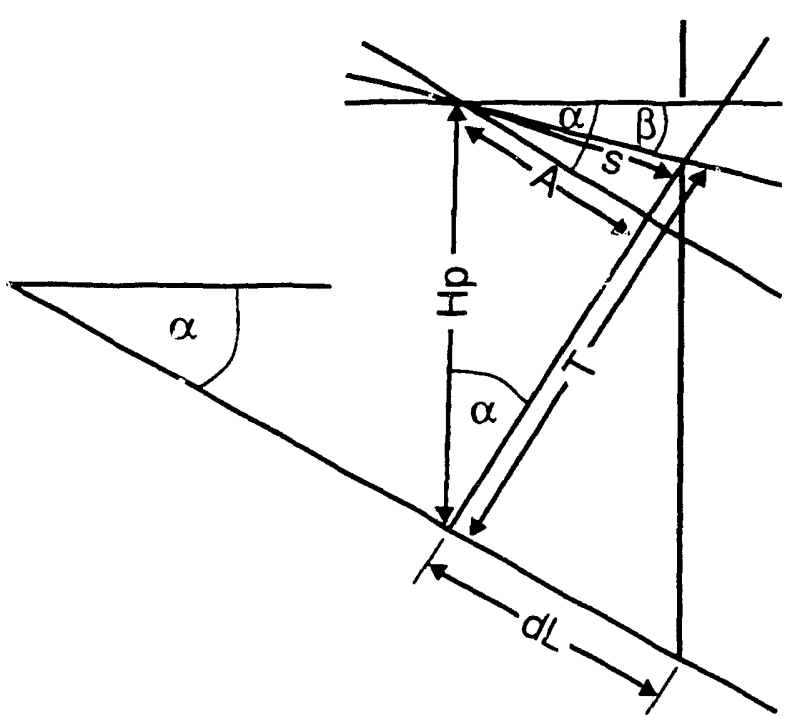

FIGURE A.1 Cross jection of Flow Segment $S$ on Sloping SPL when the Pressure-Head Gradient is Less than or Ecrual to the Elevation-Head Gradient

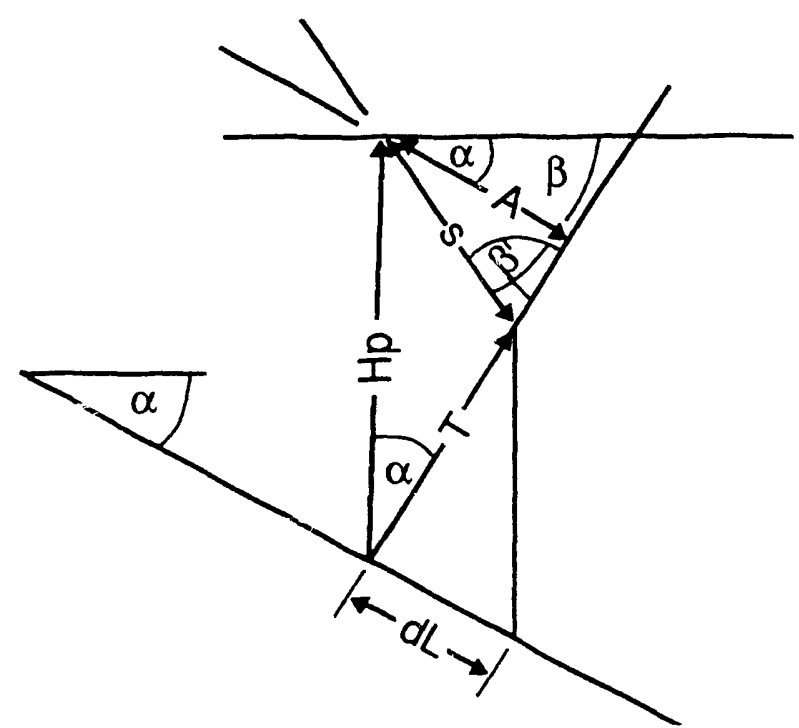

FIGURE A.2 Cross Section of Flow Segment S on Sloping SPL when the Pressure-Head Gradient is Greate. than the Elevation-Head Gradient 
Several geometric relationships can be determined from Figure A.1. The distance $\mathrm{A}$ is related to the distance $\mathrm{S}$ through:

$$
A=H p \sin \alpha=S \cos (\alpha-\beta)
$$

Solving for S yields:

$$
S=H p \sin \alpha / \cos (\alpha-\beta)
$$

The pressure read differential in the distance $\mathrm{dL}$ is

$$
\mathrm{dHp}=\mathrm{dL} \sin \alpha-\mathrm{S} \sin \beta
$$

Dividing Eq. A.3 by dL yields the pressure-head gradient:

$$
\mathrm{dHP} / \mathrm{dL}=\sin \alpha-\mathrm{S} \sin B / \mathrm{dL}
$$

When the pressure-head gradient is small, $\alpha$ and $\mathrm{dL}$ are approximately equal to $B$ and $\mathrm{S}$, respectively, and Eq. A.4 goes to zero as expected. The thickness for the flow window $\mathrm{T}$ may be computer using Eq. A.1, which can be transformed to:

$$
A=H P \sin \alpha=T /[\cot \alpha+\tan (\alpha-\beta)]
$$

Therefore $\mathrm{T}$ may be written as

$$
T=H p \sin \alpha[\cot \alpha+\tan (\alpha-\beta)]
$$

For the case $\alpha \cong B$

$$
T=H p \cos \alpha
$$

For the case $B \ll \alpha$

$$
T=H P[\cos \alpha+\sin \alpha \tan \alpha]
$$

Figure A.2 illustrates the case where the pressure-head gradient is larger than the elevation-head gradient. The angle $B$ is in this case larger than $\alpha$. Equation A.1 can be transformed to:

$$
A=H p \sin \alpha=T /\left[\cot \alpha-\cot B^{\prime}\right]
$$

where:

$$
B^{\prime}=90-(\beta-\alpha)=90-\beta+\alpha
$$


and $\mathrm{T}$ therefore becomes:

$$
\begin{aligned}
& T=H p \sin \alpha[\cot \alpha-\cot (90-\beta+\alpha)] \\
& T=H p[\cos \alpha-\sin \alpha \tan (\beta-\alpha)]
\end{aligned}
$$

\section{REFERENCE}

Childs, E.C., 1971, Drainage of Groundwater Resting on a Sloping Bed, Water Resources Research, 7(55):1256-1263. 


\section{APPENDIX B:}

ESTIMATION OF TIME TO STEADY-STATE CONDITION 


\section{APPENDIX B:}

\section{ESTIMATION OF TIME TO STEADY-STATE CONDITION}

A method for determining the approximate length of time required to reach the steady-state condition modeled in this paper can be developed. This is done by calculating the area of the saturated mound formed and then determining the time required for the infiltrating water to fill that area. A lower limit for the mound formation time can be determined by ignoring mass losses due to evaporation and leakage. When the cumulative steady-state mass losses due to evaporation and leakage are incorporated, an upper limit is calculated.

The area of saturated sediment is calculated as the sum of two smaller areas -beneath the percolation sump (area 1) and downslope of the percolation sump (area 2). Area 1 is calculated on the basis of an assumed flat phreatic surface (see Eq. 32 in Section 2 of the text) as a triangular shape:

$$
\text { Area } 1=\frac{1}{2} \text { Ho LI } \cos \alpha=\frac{1}{2} \mathrm{Ho}^{2} \cos \alpha / \sin \alpha
$$

Area 2 is calculated by integrating the pressure head Hp (see Eq. 28 in Section 2 of the text) formed on the sloping clay layer between the origin (edge of the sump) and the end of the mound L2:

$$
\text { Area } \begin{aligned}
2 & =\int_{0}^{L 2} H p d L \\
& =\int_{0}^{L 2} \frac{A}{B}\left\{\exp \left[\frac{B}{K}(L 2-L)\right]-1\right\} d L \\
& =\frac{A}{B}\left\{\frac{K}{B}\left[\left(\exp \frac{B}{K} L 2\right)-1\right]-L 2\right\}
\end{aligned}
$$

The area of the saturated sediments is the sum of areas 1 and 2:

$$
\text { Area } 1+\text { Area } 2=\frac{1}{2} \mathrm{Ho}^{2} \cos \alpha / \sin \alpha+\frac{A}{B}\left\{\frac{K}{B}\left[\left(\exp \frac{B}{K} L 2\right)-1\right]-L 2\right\}
$$

The lower limit for formation of this area is calculated by ignoring the mass losses due to evaporation from the phreatic surface and leakage through the clay layer. Equation B.3 is multiplied by $\theta$, the sediment porosity, and divided by the infiltration rate $\mathrm{K} 2 \mathrm{D}$. Dimensionally, this yields a result in time and can be represented as:

Time of mound formation $=$

$$
\frac{\theta\left\{\frac{1}{2} \mathrm{Ho}^{2} \cos \alpha / \sin \alpha+\frac{A}{B}\left[\frac{K}{B}\left\{\left(\exp \frac{B}{K} L 2\right)-1\right\}-L 2\right]\right\}}{K 2 D}
$$


To estimate an upper limit for the formation time, it is assumed that the evaporation and leakage sinks are removing mass at their steady-state rate throughout the formation of the mound. This condition is considered an extreme case and serves to double the effective area of saturated sediments. As a result, the formation time calculated by Eq. B.4 is doubled. When the sloping clay layer lies at considerable depth beneath the percolation sump, an additional saturated area, consisting of those sediments that exist between the sump bottom and the top of the saturated mound, must be incorporated into the area calculation. This additional area, termed area 3 , can be calculated as the product of the sump dimension $D$ and the distance $D^{\prime}$ between the sump bottom and the top of the mound.

$$
\text { Area } 3=D\left(D^{\prime}\right)
$$

Equation B.5 should then be added to Eq. B.3 before using Eq. B.4. In these calculations, antecedent sediment moisture has been ignored. This approximation serves to artificially increase the length of time calculated by Eq. B.4 to reach the steady-state condition. These calculations assume that the clay layer saturates instantaneously. This approximation serves to artificially decrease the length of time calculated by Eq. B.4 to reach the steady-state condition. 

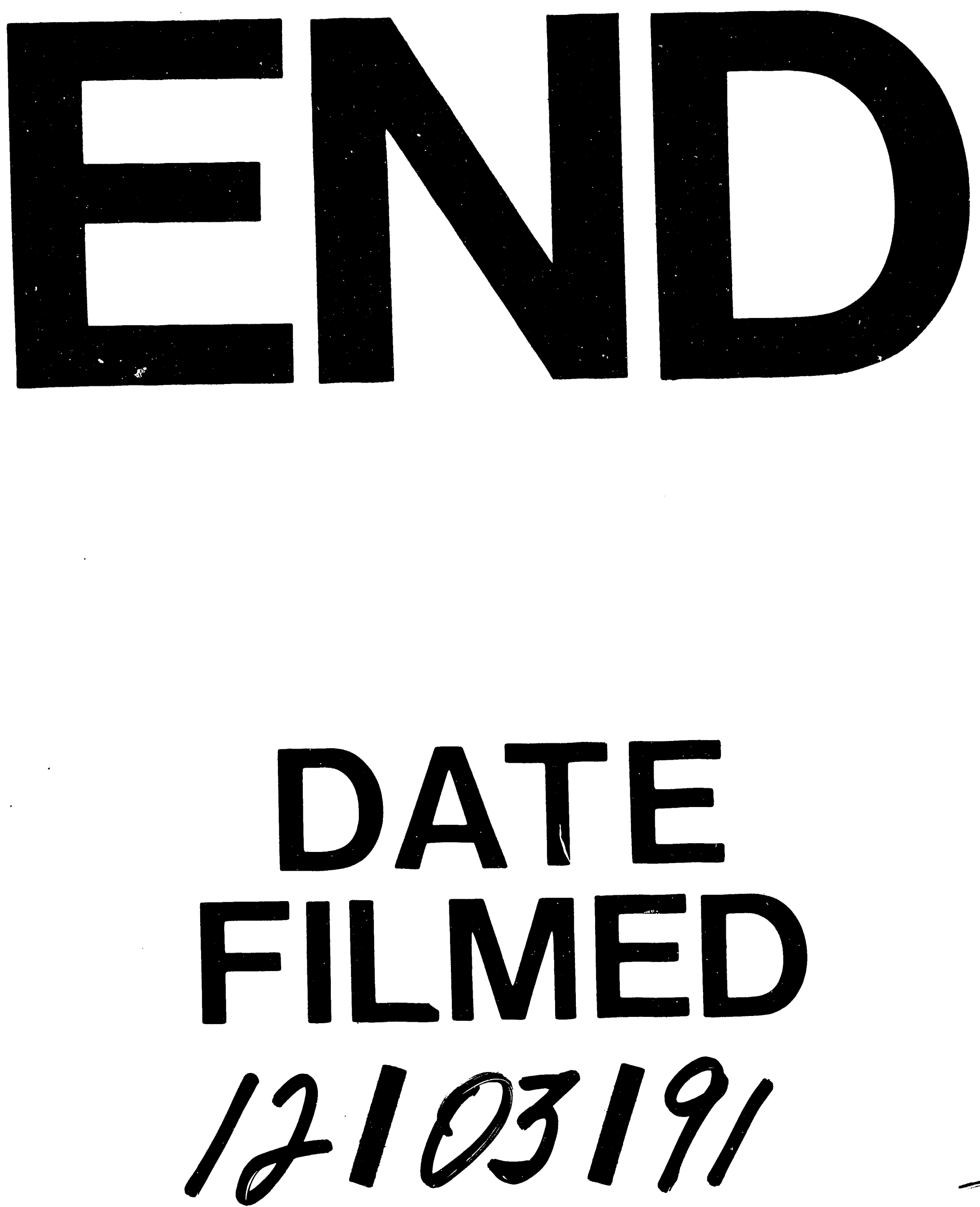
